\title{
Visualized Analysis on Research Focus and Frontiers in the Field of Chinese Enterprises Innovation
}

\author{
Xuxian Wan, Hong Wang* \\ Business School of Sichuan University \\ Chengdu, Sichuan, 610064
}

\begin{abstract}
Innovation is a strategic approach, a way to strengthen a country and a permanent theme for the sustainable development of an enterprise. In order to comprehensively understand the research trend of enterprise innovation in our country, this paper, on the basis of scientific knowledge graphic analysis method, has sorted out the evolutionary process for the research focus on enterprise innovation in our country, and conducted an exploratory analysis on the research frontiers of enterprise innovation. Research results have indicated that: the research focus is the evolution of enterprise innovation experiences in 3 periods, and the current research focus includes technical innovation, innovation performance, independent innovation, innovation capacity, and enterprise performance; exploratory innovation has become a leading topic in the research of innovation field.
\end{abstract}

Keywords-Enterprise innovation; Research focus; Research frontier; Exploratory innovation

\section{INTRODUCTION}

The Reports of the 19th National Congress of the Communist Party of China pointed out that, innovation is the first impetus leading the development and also the strategic support for building a modernized economic system. Innovation is a strategic approach, a way to strengthen a country and the permanent theme for the sustainable development of an enterprise. The concept of enterprise innovation was firstly put forward by Schumpeter, "the father of innovation"; he thought that innovation was the new combination of production elements, and those that realized "new combination" were called enterprises. Currently, the understanding about enterprise innovation not only include technical innovation, but also product innovation, management innovation, brand innovation, and the innovation of business mode. However, in the face of the big data challenge with the explosive growth of scientific knowledge, traditional literature summary is now facing a huge challenge, and it is difficult to objectively and comprehensively determine the key literature, research focus and research frontiers in the evolution process of the research field.
Since the 18th National Congress of the Communist Party of China, innovation-driven development strategies have been largely implemented, and our country has realized the great-leap-forward development of scientific and technological innovation from following it to parallel and then taking the lead, and has taken the lead in many fields in the world. Desun XIE pointed out in the Redefinition of Innovation that, it was unnecessary for Chinese enterprise innovation to walk the road of European and American enterprises, they should be combined with Chinese tradition, cultural structure and social environment. Thus, it is an urgent demand to comprehensively understand the research progress conditions of enterprise innovation field in our country. However, in the face of huge literature database, how to effectively tap and analyze the research progress in the enterprise innovation field in our country is the problem that shall be solved in this paper.

Thus, this paper is based on the CSSCI source journal articles, and then by means of CiteSpace software, it uses keywords co-occurrence, the detection of abrupt-appearance keywords and other literature calculation methods, to objectively and comprehensively show the research focus and research frontiers about the enterprise innovation field of our country, aiming to provide references for the academic research on enterprise innovation in our country.

\section{DATA SOURCE AND METHODS}

The data adopted in this research are obtained from Chinese Social Sciences Citation Index (CSSCI) Retrieval System, and the source journal is authoritative and representative. The retrieval strategies adopted for the comprehensive balance of recall and precision ratio are as follows: Name of the article="enterprise" and "innovation", time periods=years of all, literature type=papers, fuzzy retrieval; 8,422 journal articles are finally obtained, the years publishing these papers are from 1998 to 2017, and the retrieval time is November 1, 2018. This paper uses the CiteSpace software developed by Professor Chaomei CHEN from Drexel University, USA to analyze the research achievements of enterprise innovation. 


\section{ANALYSIS ON THE EVOLUTION OF RESEARCH FOCUS ON ENTERPRISE INNOVATION}

\section{Tendency Chart about the Number of Published Papers in} Enterprise Innovation Field

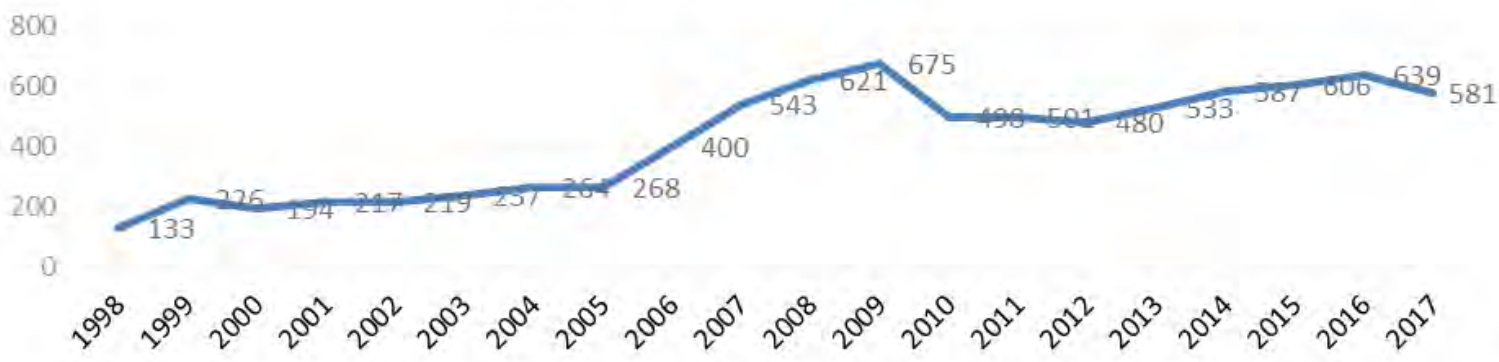

Fig. 1 Tendency Chart about the Number of Published Papers in Enterprise Innovation Field

As can be seen from the tendency chart about the number of published papers in the enterprise innovation field (as shown in Figure 1), the number of published papers in the enterprise innovation field was 133 in 1998, and then in 2005, the number of published papers was 258. In this period, although the papers about enterprise innovation increased year by year, the speed of increase was relatively slow. The number of published papers in 2006 was 400, which increased by $49.25 \%$ compared to the year of 2005 . In 2009 , the number of published papers throughout the year was 675 , reaching to the peak of the period, and then the number of published papers decreased somewhat. From 2012 to the present, each year had relatively high number of published papers and presented a trend of increase year by year. Accordingly, this paper divides the research in the enterprise innovation field into 3 periods, to discuss each period of research focus, and show the development sequence for the evolution of research focus of the enterprise innovation in our country.

Keywords are generally extracted as the core contents of a paper and can precisely indicate the core direction of the paper, and the keywords with high frequency are often used to determine the hot issues of a research field [1]. Thus, this paper uses the keyword co-occurrence graph to analyze the research focus of enterprise innovation. Since during the collection of literature, "enterprise" and "innovation" are the retrieval requirements, the occurrence frequency of "enterprise innovation", "enterprise", and "innovation" is the highest; but this is not the emphasis that is about to analyze in this paper, and is hereby neglected. Through the control panel, adjust the node threshold value, and obtain the keyword co-occurrence knowledge graph of 3 periods. Export the result of the keyword co-occurrence graph and Table 1 was obtained after sort-out. As a result of promoting the evolution of research focus in the field of enterprise innovation, it not only lies in the knowledge cross-link within the discipline, for example, applying internet structure, organizational behavior and other theories to the research of enterprise innovation, but also can be influenced by major external events. This paper starts from macroscopic perspective, and combines major external events to elaborate the research focus development sequence of enterprise innovation in our country.

TABLE I List of keywords that ranks top 10 in co-occurrence frequency

\begin{tabular}{|c|c|c|c|c|c|}
\hline $1998-2005$ & & $2006-2011$ & & 2012-the present & \\
\hline $\begin{array}{l}\text { Co-occurrence } \\
\text { frequency }\end{array}$ & Keywords & $\begin{array}{l}\text { Co-occurrence } \\
\text { frequency }\end{array}$ & Keywords & $\begin{array}{l}\text { Co-occurrence } \\
\text { frequency }\end{array}$ & Keywords \\
\hline 517 & Technical innovation & 582 & Technical innovation & 366 & Technical innovation \\
\hline 130 & SMEs & 327 & Independent innovation & 280 & Innovation performance \\
\hline 118 & System innovation & 190 & SMEs & 115 & SMEs \\
\hline 115 & Enterprise technical innovation & 106 & $\begin{array}{l}\text { Enterprise } \\
\text { innovation }\end{array}$ & 102 & Independent innovation \\
\hline 109 & Enterprise management & 93 & Innovation capacity & 78 & Innovation capacity \\
\hline 93 & Management innovation & 92 & independent & 72 & Innovative enterprises \\
\hline 84 & State-owned enterprise & 77 & Innovation performance & 70 & Enterprise performance \\
\hline 54 & Knowledge economy & 74 & Technical innovation capacity 7 & 70 & Open innovation \\
\hline 43 & Enterprise culture & 74 & $\begin{array}{l}\text { Independent } \\
\text { capability }\end{array}$ & 66 & Collaborative innovation \\
\hline
\end{tabular}

Data source: Export and Sort-out of Keyword Co-occurrence Graph Summary Sheet 
In 1997, the Reports of the 15th National Congress of the Communist Party of China clearly pointed out that, the establishment of the modernized enterprise system is the reform direction of state-owned enterprises. In 1999, our country's government put forward the Decision of CPC Central Committee and the State Council about Reinforcing Technical Innovation, Developing High Technology and Realizing Industrialization, and this decision has completely defined technical innovation, and point out the direction of accelerating the technical innovation development in our country. Regard this as the research background, from 1998 to 2005, the research focus of the enterprise innovation field included technical innovation, SMEs, system innovation, enterprise management, management innovation, and state-owned enterprises, etc.

2006 National Scientific and Technological Conference put forward the strategy of independent innovation and building an innovation-type country, and released the Outline of the National Program for Long-and Medium-term Scientific and Technological Development (2006-2020), which had promoted the research on independent innovation and enterprise innovation capacity to some extent. From 2006 to 2011, the research focus of the period included technical innovation, SMEs, independent innovation, innovation capacity, and innovation performance.
In 2012, the Reports of the 18th National Congress of the Communist Party of China clearly put forward the strategy of implementing innovation-driven development. It emphasized that scientific and technological innovation were the strategic support for improving social productivity and the comprehensive national strength, and must be placed at the core position in the overall national development. From 2012 to the present, scholars have focused on studying the innovational efficiency and effects; when being compared with the last period, the co-occurrence frequency of innovation performance increased hugely. During the period, technical innovation, independent innovation, innovation capacity and innovation performance were still the research focus; meanwhile, enterprise performance and the influence factors have become the new research focus in the period.

\section{ANALYSIS ON THE RESEARCH FRONTIERS OF ENTERPRISE INNOVATION}

Even if there are no eye-catching quotations in a new research frontier, it can also be shown in the graph. The academic circles often use "abrupt-appearance word detection" to determine relevant research frontiers. The bigger the change strength is, the more obvious the research frontier trend of relevant themes carried out around the keyword will be. Thus, this paper uses the detection of abrupt-appearance keywords from 2012 to 2017 and then obtained the visualization result as shown in Figure 2.

\section{Top 20 Keywords with the Strongest Citation Bursts}

\begin{tabular}{|c|c|c|c|c|c|}
\hline Keywords & Year & Strength & Begin & End & $2012-2017$ \\
\hline 产业集群 & 2012 & 4.3187 & 2012 & 2013 & \\
\hline 社会网络 & 2012 & 3.3812 & 2012 & 2013 & \\
\hline 商止模式 & 2012 & 3.7209 & 2012 & 2013 & \\
\hline 自主创新 & 2012 & 6.1318 & 2012 & 2013 & \\
\hline 知识管理 & 2012 & 3.7628 & 2012 & 2014 & \\
\hline 自主创新能力 & 2012 & 2.5953 & 2012 & 2013 & \\
\hline 集群企业 & 2012 & 3.6157 & 2013 & 2014 & \\
\hline 科技型小微企业 & 2012 & 5.4279 & 2013 & 2014 & \\
\hline 中介效应 & 2012 & 3.6157 & 2013 & 2014 & \\
\hline 科技型企业 & 2012 & 3.4052 & 2014 & 2015 & \\
\hline 价值链 & 2012 & 3.4052 & 2014 & 2015 & \\
\hline 创新驱动 & 2012 & 3.0302 & 2014 & 2015 & \\
\hline 民壱企业 & 2012 & 3.7163 & 2014 & 2015 & \\
\hline 组织几余 & 2012 & 3.2694 & 2015 & 2017 & \\
\hline 技术创新效率 & 2012 & 3.34 & 2015 & 2017 & \\
\hline 生态创新 & 2012 & 2.971 & 2015 & 2017 & \\
\hline 研岁投入 & 2012 & 3.4694 & 2015 & 2017 & \\
\hline 制度环境 & 2012 & 3.34 & 2015 & 2017 & \\
\hline 环境规制 & 2012 & 2.2719 & 2015 & 2017 & \\
\hline 探索式创新 & 2012 & 4.0608 & 2015 & 2017 & \\
\hline
\end{tabular}

Fig. 2 Abrupt-appearance keywords in the enterprise innovation field

As can be seen from Figure 2, from 2012 to 2017, there were totally 20 abrupt-appearance keywords, and during the abrupt-appearance of exploratory innovation, it lasts to the present with the strongest change strength (4.0608), indicating that the trend of becoming the research frontier in the enterprise innovation field is quite obvious. This paper will combine representative quotation and literature, focus on elaborating the scientific and technological achievements of 
exploratory innovation, and put forward further research suggestions to provide references for the follow-up research in the enterprise innovation field.

Citations
0
0
0
0
0
0
0
0
0
0
0
0
0
0
0
0
0

\author{
Citing Article \\ 付丙海, 2015, 中国软科学, V,P176 \\ 何建洪, 2015, 科技管理研究, V35, P7 \\ 俞位增, 2015, 江西社会科学, V, P59 \\ 刘㗂, 2016, 经济管理, V38, P68 \\ 吴亮, 2016 , 科学学与科学技术管理, V37, P75 \\ 吴亮, 2016, 管理学报, V13, P425 \\ 徐虂壬, 2017 , 管理学报, V14, P221 \\ 离德明, 2015 , 管理学报, V12, P1479 \\ 音萍, 2016 , 经济管理, V38, P14 \\ 永宁捐, 2017 , 科学学与科学技术管理, V38, P108 \\ 林明, 2015, 科研管理, V36, P65 \\ 毕晓方, 2017 , 会计研究, V,P46 \\ 汪涛，2017, 科技进步与对策, V34, P80 \\ 王德胜, 2016, 中国软科学, V,P114 \\ 王朝晖, 2016 , 科学学与科学技术管理, V37, P159 \\ 形新朋, 2016 , 科技管理研究, V36, P1 \\ 陈立要, 2015 , 软科学, V29, P9
}

Fig. 3 Quoted Literatures about Exploratory Innovation

Exploratory innovation is the exploration and attempt at new products, new technologies and new things, and an innovative mode of conducting the essential reforms in technologies or products. Being different from the exploratory innovation, exploitative innovation is an innovation mode with gradual change nature, and conducts adjustment and improvement on the basis of the original product and technology. The dual innovation mode includes exploratory innovation and exploitative innovation. As for the research on the exploratory innovation, it is conductive to provide references for enterprises in the selection of innovation mode, and is also helpful for implementing the innovative state strategies of our country. The exported citing articles about exploratory innovation in the paper (refer to Figure 3), deeply analyze the research achievements of the citing articles, and currently, the research about exploratory innovation is carried out mainly focusing on the clue of "influence factors--selection of innovation mode-enterprise performance".

The representative research achievements in the selective research on the influence factors and innovation modes mainly include: Jianhong HE, Dongmei CAI, and Zeling WANG[2] found out that when the enterprise's network capacity was strong, the exploratory innovation strategies were more conductive to the formation of innovative enterprises, when compared with exploitative innovation strategies. Deming ZENG and Jinyan WEN[3] held that the collaborative R\&D network centrality and the two types of innovation keep a upended U-shaped relationship. Desheng WANG, Jie XIN and Chuang WU[4] started from the theoretical mode of "strategic orientation--innovation--performance", and held that strategic orientation can exert an important influence on the dual innovation selection of enterprises. Xiaofang BI, Shuping ZHAI, and Baoqiang JIANG[5] used the listed high-tech enterprises as the samples, to study the direct effect and complementary effect of financial redundancy and government subsidies on the enterprise dual-innovation investment. Ping ZENG, Yang LIU, and Xiaojie WU[6] introduced system scenario, and studied the influence of government support on enterprise innovation mode. Xin LIU and Chunyan JIANG[7] studied the influence of government and business network relationship on enterprise exploratory innovation.

As for the research about the innovation mode for enterprise's innovation performance, scholars studied the respective influence of exploitative and exploratory innovation on performance as well as the interactive influence of two innovation modes on the performance. However, there haven't had any consistent conclusion yet in the influence effect. Tao WANG, Fanrong WANG, and Weiran CHEN [8](2017) held that open innovation (exploitative innovation) and exploratory innovation can exert a positive influence on innovation performance, and the former has a greater effect, but their interaction can exert an obvious negative effect on the innovation performance. Xinpeng XING and Dapeng LIANG[9](2016) held that open innovation and exploratory innovation as well as the balance of the two can obviously promote the performance of start-up enterprises, but exploratory innovation is more conductive to the improvement of enterprise performance Liang WU, Xinglu ZHAO, and Jianqi ZHANG[10](2016) tried to analyze the action mechanism of innovation mode on the performance, and held that resource patchwork activities in the relationship between dual-innovation strategies (exploratory innovation and exploitative innovation) and enterprise performance play the key intermediary role.

To sum up, exploratory innovation and exploitative innovation modes are quite different in the aspects of risk, resource investment and the target. As for the research about 
the influence factors of innovation mode, it pays more attention to the external enterprise factor influence on the enterprise innovation mode; As for the research on the relationship between innovation mode and performance, it pays more attention to the short-term benefits. Thus, this paper holds that, it is applicable to combine the capital market of our country, and further study the relationship and effect mechanism of "innovation mode--enterprise performance--enterprise value", to realize the sustainable development objective of enterprises.

\section{CONCLUSION}

This paper regards the journal papers of enterprise innovation field collected by CSSCI database as the main data source, and then by means of CiteSpace software, it conducts visualized analysis on the research focus and frontiers about enterprise innovation in our country. The main research conclusions are as follows:

(1) In combination with the tendency chart about the number of published papers in enterprise innovation field and the major external events, divide the research process of enterprise innovation into 3 periods, use the keywords co-occurrence method, to show the development sequence for research focus, and get the result that technical innovation, SMEs, innovation performance, independent innovation, innovation capacity, enterprise performance, and influence factors are the research focus in the enterprise innovation field.

(2) Use the abrupt-appearance keyword detection technology to get the result that exploratory innovation will become the research frontier in the enterprise innovation field. With respect to the exploratory innovation, it is applicable to combine the capital market, further study the relationship and effect mechanism of "innovation mode--enterprise performance-enterprise value", and then realize enterprises' sustainable development, enrich the research achievements of enterprise innovation and provide bases for the decision-making of enterprise innovation.

\section{ACKNOWLEDGMENT}

Fund project: National Social Science Fund Project about "Linkage and Coordinated Research on the Tax Reform, Tax-sharing System and Enterprises' Tax Burden Pressure after 'Replacing Sales Tax with Value-added tax'" (Project No.: 17BJY176); Chengdu Soft Scientific Research Project about "Innovation and Entrepreneurship Tax Incentive Policy Research" (Project No.: 2015-RK00-00268-ZF)

\section{About the author:}

Xuxian WAN (1987-), female, born in Wenzhou, Zhejiang, a doctoral student from the Business School of Sichuan University, a certified public accountant, international certified internal auditor, and management accountant registered in USA; her research direction is innovation and entrepreneurship as well as the sustainable development of enterprises and the corporate finance;

\section{REFERENCES}

[1] Jie LI and Chaomei CHEN. Citespace Technical Text Exploration and Visualization[M] Capital Economic and Trade University Press, 2016.

[2] Jianhong HE, Dongmei CAI, and Zeling WANG. Formation of Innovative Enterprises: Case Research Based on Network Capacity and Innovative Strategies[J]. Science and Technology Management Research. 2015(09): 7-12.

[3] Deming ZENG and Jinyan WEN. Influence of Collaborative R\&D Network Centrality, and Knowledge Distance on the Enterprise's Dual Innovation[J]. Chinese Journal of Management. 2015(10): 1479-1486.

[4] Desheng WANG, Jie XIN, and Chuang WU. Strategic Orientation, Amphibious Innovation and Enterprise Performance[J]. China Soft Science. 2016(02): 114-125.

[5] Xiaofang BI, Shuping ZHAI, and Baoqiang JIANG. Influence of Government Subsidies, and Financial Redundancy on the Dual Innovation of High-tech Enterprises[J]. Accounting Research. 2017(01): 46-52.

[6] Ping ZENG, Ziwei HUANG, and Xiuyun XIA. Influence of External Network on Enterprises' Dual Innovation: Regulatory Effect of System Environment and Enterprise Feature $[\mathrm{J}]$. Research and Development Management. 2017(05): 113-122.

[7] Xin LIU and Chunyan JIANG. Political and Business Network Relationship and Enterprise Exploratory Innovation: One Integration Model[J]. Economic Management. 2016(08): 68-81.

[8] Tao WANG, Fanrong WANG, Weiran CHEN. Influence of Emerging Enterprise Innovation Mode on Innovation Performance under Open Innovation Background[J]. Science \& Technology Progress and Countermeasures. 2017(02): 80-86.

[9] Xinpeng XING, and Dapeng LIANG. Developmental Innovation, Exploratory Innovation and Balanced Innovation, Omitted, and Consequences, Environmental Turbulence and the Start-up Enterprise Performance $[\mathrm{J}]$. Science and Technology Management Research. 2016(13).

[10] Liang WU, Xinglu ZHAO and Jianqi ZHANG. Research on the Relationship between Dual Innovation and Enterprise Performance With Resource Patchwork as an Intermediary Process[J]. Chinese Journal of Management. 2016(03): 425-431. 